Ключевые слова: земельный участок, фактические границы земельного участка, определение грании земельного участка, ограждения, заборы.

\title{
PROBLEM ISSUES OF LAND AND TECHNICAL EXAMINATION IN DETERMINING BOUNDARIES OF NEIGHBORING LAND PLOTS
}

\section{Taranets T. A.}

The paper analyzes the issues of land and technical examination and expert researches concerning establishment of factual boundaries of neighboring land plots. Normative legal acts which govern the establishment of land plots boundaries and their exploitation, are listed. Thus, it's underlined that in carrying out research on the compliance of the established boundaries of neighboring land plots with the requirements of the land legislation, an expert should define to whom from the neighbors belong the barriers, fences, buildings, constructions and linear structures, which determine the factual boundaries, as well as, whether an increase of buildings walls thickness in which the common boundary passes as a result of an external arrangement of walls warming and their facing with facade systems. This is achieved by interviewing neighbors and compiling an appropriate application for matching this issue with the customer of research. It's also necessary to examine the contracts on joint installation of real estate objects on the joint border or permission for the installation of real estate objects in an alien land plot. At the same time it's indicated that in the absence of such permits and agreements, factual boundary of the land plot should be considered an external plane of buildings and constructions, taking into account arrangement of external walls warming and their facing with facade systems, and also external planes which pass on the most protruding points of barriers, fences and linear structures constructions, belonging to the owner of the real estate. The author proposes to update the expert methodological basis relating to the disturbances of adjacent land use borders.

Keywords: land plot, factual boundaries of the land plot, delimitation of the land plot boundaries, barriers, fences.

УДК 533.6, 614.841

A. В. Васильченко, доцент Национального университета гражданской защиты Украины, кандидат технических наук, доцент,

И. Н. Рябинин, главный судебный эксперт Харьковского НИЭКЦ МВД Украины,

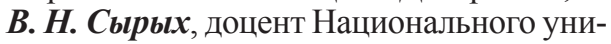
верситета гражданской защиты Украины, кандидат технических наук, доцент

\section{МОДЕЛЬ РАСПРОСТРАНЕНИЯ УДАРНОЙ ВОЛНЫ В КОММУНИКАЦИОННЫХ ПОМЕЩЕНИЯХ}

Предложена физическая модель образования и распространения ударной волны в коммуникационном помещеении, как в канале со стенками разной жесткости. Обоснована необходимость устройства легкосбрасываемых

(C) Васильченко А. В., Рябинин И. Н., Сырых В. Н., 2016 
конструкиий в коммуникационных помещениях зданий с повыщенной взрывоопасностью.

Ключевые слова: физическая модель, ударная волна, коммуникационное помещение, взрывоопасность, легкосбрасываемая конструкиия.

При обследовании строительных объектов, пострадавших в результате аварийных взрывов, часто возникает необходимость объяснения причин видимых повреждений строительных конструкций. В промышленных зданиях категорий «А» и «Б», как правило, основное внимание при проектировании уделяется помещениям с повышенной взрыво- и пожароопасностью. Их оснащают легкосбрасываемыми конструкциями (ЛСК), которые чаще всего располагают в оконных и дверных проемах. В случае аварийного взрыва ударная волна (УВ) разрушает ЛСК, и избыточное давление в помещении быстро уменьшается. Конструкции в таких помещениях рассчитывают на возможное воздействие взрыва, а в коммуникационных помещениях, где после преодоления ЛСК распространяется УВ, и строительные конструкции подвергаются ее воздействию, каков будет результат трудно предсказать. Имеется в виду избирательность разрушительного действия УВ, когда одни строительные конструкции на пути ее движения разрушаются, а другие, аналогичные, остаются практически неповрежденными. Также важной проблемой является повышение безопасности в коммуникационных помещениях, куда проникла и где распространяется УВ, снижение избыточного давления на ее фронте.

Примером коммуникационных помещений могут быть коридоры, туннели, которые в промышленных зданиях достигают значительной длины. Коридор можно представить как полузамкнутое пространство (канал), в котором энергия УВ рассеивается медленнее, чем в большом помещении или на открытом пространстве ${ }^{1}$. При этом повышаются потери энергии на нагрев воздуха и трение при взаимодействии УВ со стенками канала. Стенки канала, как поверхности отражения, также влияют на процесс образования и распространения УВ, определяя ее интенсивность. В этом смысле интерес представляет изучение взаимодействия стен (перегородок) коридора с УВ для прогнозирования поведения этих строительных конструкций при взрыве. В известных публикациях рассматриваются проблемы учета поведения УВ в каналах с изменяющимся сечением, но при этом предполагается, что их стенки одинаково жесткие ${ }^{2}$. Однако в реальных строительных объектах стены коридоров часто различаются и конструктивно, и по материалам.

Данная работа посвящена формулированию рекомендаций по повышению безопасности для строительных конструкций коммуникационных

1 См.: Селиванов В. В. Ударные и детонационные волны. Методы исследования / В. В. Селиванов, В. С. Соловьев, Н. Н. Сысоев. - М. : Изд-во МГУ, 1990. — 256 с.

2 См.: Шевляков А. Г. Расчет составной строительной конструкции на динамическую нагрузку, создаваемую плоской волной давления / А. Г. Шевляков // Архитектура оболочек и прочностной расчет тонкостенных строительных и машиностроительных конструкций сложной формы : тез. докл. Междунар. науч. конф. - М. : Изд-во РУДН, 2001. - С. 81-82. 
помещений зданий с повышенной взрывоопасностью на основании формирования физической модели образования и распространения ударной волны в канале со стенками разной жесткости, т. е. когда одна из стен заметно деформируется по сравнению с другой.

Для демонстрации образования и распространения УВ в канале с жесткими стенками используется модель, показанная на рисунке а). После взрыва в начале канала образуется криволинейная поверхность фронта ударной волны. Падающая ударная волна (ПУВ) распространяется в невозмущенной воздушной среде, а отраженные ударные волны (ОУВ) - в среде сжатой и нагретой прошедшей ПУВ. В этих условиях ОУВ имеют бо́льшие скорости, нежели ПУВ, и имеют возможность ее догонять и сливаться с ней. Участок, на котором ОУВ сливаются с ПУВ, называют «тройной точкой». В описываемом процессе тройные точки, возникая у поверхности канала, перемещаются к его центру; в результате происходит полное слияние ОУВ с ПУВ, и образуется головная ударная волна (ГУВ) с плоским фронтом. Динамическое давление на фронте ГУВ значительно превышает давления на фронтах отраженных и падающей ударных волн. Формирование плоского фронта ГУВ происходит в зоне 4-8-ми характерных размеров сечения канала.

Существуют эмпирические зависимости для характеристик ГУВ в канале с жесткими стенками ${ }^{1}$ :

$$
\begin{gathered}
\Delta p=\left(a \frac{f m}{x S}+b \sqrt{\frac{f m}{x S}}\right) e^{-\beta x} ; \\
I=c \frac{f m}{S} e^{-\frac{\beta x}{2 d}} \\
\tau=q \frac{x}{c_{0}} \sqrt[6]{\frac{f m}{x S}},
\end{gathered}
$$

где $\Delta p$ - избыточное давление, МПа; $I$ - удельный импульс, Па с ; $\tau$ - время фазы сжатия, с; $a, b, c, q$ - эмпирические коэффициенты; $f$ - коэффициент эффективности взрывчатого вещества по сравнению с тротилом; $m$ - масса взрывчатого вещества, кг; $x$ - расстояние, пройденное УВ, м; $S$ - площадь сечения канала, ${ }^{2} ; \beta$ - приведенный коэффициент аэродинамического сопротивления канала; $d$ - приведенная ширина канала, м; $c_{o}-$ скорость звука, м/с.

При прохождении УВ стенки канала испытывают нагрузку, которая характеризуется приведенным давлением $\bar{p}$

$$
\bar{p}=\frac{p F \sqrt{E}}{A \sqrt{R^{3}}}
$$

1 См.: Взрывные явления: оценка и последствия : в 2-х кн. : пер. с англ. / [У. Бейкер, П. Кокс, П. Уэстрайн и др.] ; под ред. Я. Б. Зельдовича, Б. Е. Гельфанда. - М. : Мир, 1986. - Кн. 1. - 319 с. 
и приведенным импульсом $\bar{I}$

$$
\bar{I}=\frac{I h \sqrt{E}}{A R \sqrt{\rho}},
$$

где $F$ - площадь воздействия УВ, м $^{2} ; E$ - модуль упругости материала стенки, МПа; $h$ - толщина стенки, м; $A$ - площадь сечения стенки, $\mathbf{m}^{2} ; R$ - предел прочности материала стенки, МПа; $\rho$ - плотность материала стенки, H/M².

Анализ представленных формул показывает, что если противоположные стенки конструктивно разные и состоят из разных материалов, но их относительная деформация при воздействии УВ невелика $\left(R_{2} \approx R_{1} ; E_{2} \approx E_{1}\right)$, то распространение УВ в канале происходит по механизму, показанному на рисунке а).

Если же одна из стенок канала подвижна и/или легко деформируется $\left(R_{2}<R_{1} ; E_{2}<E_{1}\right)$, то приведенный импульс, действующий на нее, уменьшается. Следовательно, уменьшается скорость ОУВ, увеличивается зона формирования плоского фронта ГУВ, и при этом фронт УВ как бы разворачивается в сторону нежесткой стенки (рисунок б). Давление на эту стенку дополнительно увеличивается, что может привести к ее разрушению.

Но наряду с этим нарушается и геометрия плоского фронта ГУВ, а для формирования нового плоского фронта требуется зона длиной 4-8 характерных размеров сечения канала. Здесь также необходимо учитывать, что на разрушение стенки и формирование нового плоского фронта ГУВ дополнительно расходуется энергия. Степень ослабления УВ зависит от величины повреждения стенки, т. е. от отношения площади участка разрушения стенки к площади сечения канала.

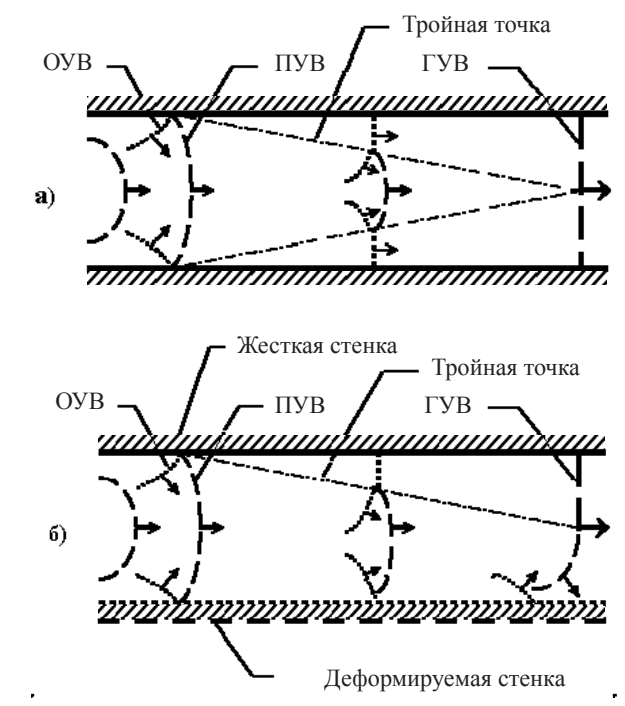

Рисунок. Модель образования и распространения УВ в канале:

a) с жесткими стенками; б) с жесткой и деформируемой стенками 
Рассмотренная модель объясняет поведение строительных конструкций в коммуникационных помещениях большой длины при воздействии на них УВ. Если в коридоре одна стенка сформирована капитальной стеной, а другая - перегородкой со значительно меньшей жесткостью, то при прохождении УВ по длине коридора перегородка разрушается фрагментарно по зонам возможного формирования плоского фронта ГУВ. Причем, после разрушенного участка перегородки может следовать участок с минимальными повреждениями.

Предложенная модель позволяет обосновать способ повышения безопасности в коммуникационных помещениях зданий с повышенной взрывоопасностью. Для этого необходимо вдоль коммуникационного помещения с интервалом 4-8 размеров ширины этого помещения предусмотреть легкосбрасываемые конструкции в виде вставок (перегородок), закрывающих расширители. Такое устройство коммуникационных помещений будет препятствовать образованию ГУВ, способствовать снижению избыточного давления на фронте УВ и ее затуханию.

Предложенная физическая модель формирования и распространения УВ в канале со стенками разной жесткости может быть применена для объяснения разной степени повреждений строительных конструкций в коммуникационных помещениях при взрывах. Эту модель также можно использовать при построении алгоритма численного расчета распространения УВ в канале со стенками разной жесткости.

Представленная модель показывает, что в коммуникационных помещениях строительных объектов, в которых вероятны аварийные внутренние взрывы, для повышения безопасности следует предусматривать легкосбрасываемые конструкции. Располагать легкосбрасываемые конструкции следует вдоль коммуникационного помещения с интервалом в 4-8 размеров ширины этого помещения.

\title{
МОДЕЛЬ ПОШИРЕННЯ УДАРНОЇ ХВИЛІ В КОМУНІКАЦІЙНИХ ПРИМІЩЕННЯХ
}

\section{Васильченко О. В., Рябінін І. М., Сирих В. М.}

Запропоновано фізичну модель утворення й потирення ударної хвилі в комунікаиійному приміщенні як у каналі зі стінками різної жорсткості. Обтрунтовано необхідність улаштування легкоскиданих конструкцій у комунікачійних приміщеннях будівель із підвищеною вибухонебезпекою.

Ключові слова: фізична модель, ударна хвиля, комунікаиійне приміщення, вибухонебезпека, легкоскидана конструкиія.

\section{MODEL OF SHOCK WAVES PROPAGATION IN THE COMMUNICATION PREMISES}

\author{
Vasylchenko O. V., Riabinin I. M., Syryh V. M.
}

During examination of construction sites affected by emergency explosions, it often becomes necessary to explain the reasons of visible damages of building constructions. The paper attempts to explain the selectivity of the destructive action of the shock wave in 
the communication premises of the industrial buildings where some building constructions in the way of movement are destroyed, others remain practically unchanged. The physical model of the formation and distribution of shock wave in communicational premises as in the channel with walls of varying rigidity is proposed. It is shown that if one of the channel walls is easily deformed, then it causes turn of the main shock wave to this wall and the pressure increase that may lead to destruction of the wall portion. But simultaneously with it, the geometry of the plane front of the main shock wave is disturbed, and the zone of the length of 4-8 typical dimensions of the channel cross section is required for the formation of a new planar front. Therefore, the passage of a shock wave through the length of the corridor, the wall with lower rigidity is destroyed fragmentarily. The proposed physical model may be used to construct an algorithm of numerical calculation of shock wave propagation in a channel with walls of different rigidity. On the basis of the considered physical model, a way to increase safety in communication premises where a shock wave may propagate, is proposed. For this, easily droppable constructions should be placed along the communication premises at intervals of 4-8 dimensions of these premises width.

Keywords: physical model, shock wave, communications premises, explosion hazard, easily droppable construction.

УДК 614.841

B. H. Cырых, доцент Национального университета гражданской защиты Украины, кандидат технических наук, доцент,

A. В. Васильченко, доцент Национального университета гражданской защиты Украины, кандидат технических наук, доцент

\section{АНАЛИЗ ОПАСНОСТИ ПРИ ВЗРЫВЕ МЕТАНОВОГО БАЛЛОНА}

Рассмотрены особенности взрыва 50-ти и 80-литровых метановых баллонов при различных эксплуатационных температурах. Рассчитаны параметры взрывов метановоздушной смеси: радиус огненного шара, скорость его распространения, количество выделившейся тепловой энергии. Проанализирована пожарная опасность при повреждении метановых баллонов автотранспортных средств.

Ключевые слова: метан, баллон, метановоздушная смесь, взрыв.

В Украине в последнее время наблюдается значительный рост использования метановых газовых баллонов для газотопливных систем транспортных средств. Метан используется как альтернативное топливо для автомобилей благодаря дешевизне и стабильным показателям качества. Хранится он в сжатом виде в металлических, металлопластиковых или композитных баллонах объемом от 25 до 80 л.

При интенсивной и длительной эксплуатации баллоны могут повреждаться в результате коррозии и механических воздействий, а также из-за ослабления контроля за их состоянием при эксплуатации, что может послу-

(C) Сырых В. Н., Васильченко А. В., 2016 